\title{
Can Disruptive Technologies, On-Demand Mobility, and Biofuels Improve Transportation Environmental Sustainability? A Review of Recent Research
}

\author{
Mikhail V. Chester $^{1}$
}

Published online: 8 July 2015

(C) Springer International Publishing AG 2015

\begin{abstract}
As new transportation technologies, travel behaviors, and fuels emerge, there is opportunity to proactively assess environmental impacts to ensure that reductions occur and unintended tradeoffs are avoided. This article summarizes the goals, scope, and findings of a special issue on transportation sustainability. The special issue provides an overview of recent research and policies on autonomous vehicles, electric vehicles, on-demand mobility (including carsharing), intelligent transportation systems, and biofuels and their expected environmental effects. The reviews show that there are efforts underway to understand the environmental impacts of changes in transportation systems that may lead to technology designs and deployment strategies for environmental sustainability.
\end{abstract}

Keywords Transportation · Environmental Sustainability . Autonomous/electric vehicles $\cdot$ Carsharing $\cdot$ Intelligent transportation systems $\cdot$ Biofuels

\section{Introduction}

The movement of people or goods is generally associated with increases in welfare, but there is increasing scrutiny of the unintended impacts of our transportation systems. Many

This article is part of the Topical Collection on Transportation

Mikhail V. Chester

mchester@asu.edu

1 Civil, Environmental, and Sustainable Engineering, Arizona State University, 660 South College Avenue, P.O. Box 873005, Tempe, AZ 85287-3005, USA researchers and practitioners have embraced sustainability principles to better characterize these impacts and develop recommendations to reduce these impacts into the future. Impacts are often assessed across economic development, environmental integrity, and social quality of life dimensions [4]. Sustainability's basic goal is one of welfare, in the context of inter-generational equity [5], and transportation services while improving welfare in the short run may produce environmental and health impacts that compromise welfare in the long run. Transportation services often account for a large share of environmental impacts at national, regional, and local scales; are mobile; are distributed, and are largely the result of individual or firm decisions raising challenging questions of how to achieve large-scale reductions. Furthermore, as developing countries automobilize, there is the potential for major environmental consequences [3]. Yet several disruptive technologies, on-demand mobility, and biofuels offer the potential to significantly affect the energy use and environmental impacts of transportation systems.

This special issue brings together articles that explore the recent advances in the study of automated vehicles, electric vehicles, intelligent transportation systems (ITS), on-demand mobility (including carsharing), and biofuels for transportation environmental sustainability. The article reviews key technologies, changes in behavior, and fuels that may transform mobility services and characterize where we are in our understanding of their environmental impacts. A word cloud showing keyword metadata from the four special issue articles is shown in Fig. 1.

\section{Special Issue Overview}

The articles in this special issue show that transportation researchers are making important strides in anticipating the 
Fig. 1 Special issue word cloud. The most common relevant words from the four articles in the special issue are shown with their size indicating the number of times they appear

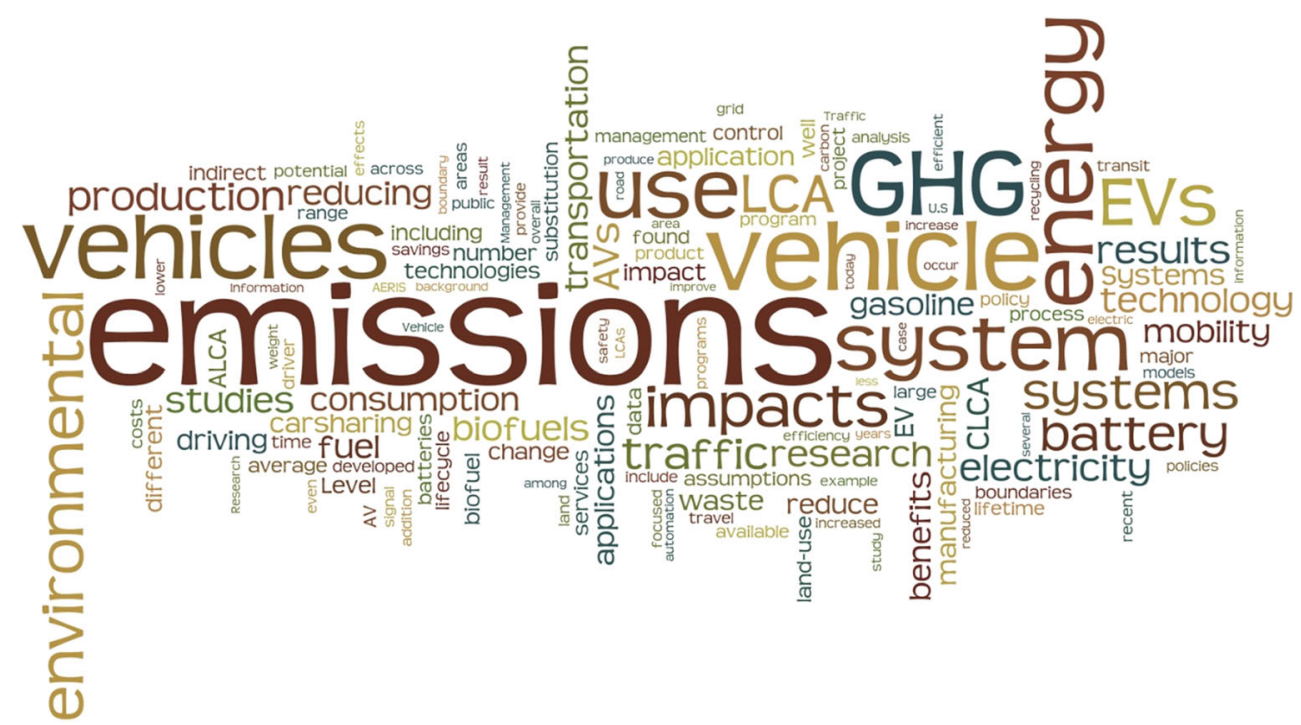

environmental impacts of emerging technologies, changing travel behaviors, and biofuels that will hopefully lead to proactive recommendations to policy and decision makers. The articles focus on passenger transportation and are briefly summarized here.

Greenblatt and Shaheen [2] characterize the potential of autonomous vehicles and on-demand mobility (also known as carsharing, ridesharing, ridesourcing, or e-hail services) to reduce energy use and greenhouse gas emissions. With autonomous vehicle technology rapidly improving, costs decreasing, and on-demand vehicle travel increasing, they discuss how changes in personal vehicle use could impact vehicle kilometers of travel.

Nealer and Hendrickson [7] examine electric vehicle energy use and air emissions by assessing critical processes within the life cycle. They report that while life cycle processes (in particular batteries) are significant in the environmental performance of electric vehicle use, electricity generation for propulsion typically amounts to a large portion of greenhouse gas emissions. They discuss the current debate around the use of average versus marginal electricity generation emission factors, the use of which can significantly change the greenhouse gas performance of electric vehicles. The challenges of accurately estimating driving behavior in electric vehicles are also discussed, as well as the effects of battery technologies in the life cycle. Nealer and Hendrickson go on to discuss several policies that may advance electric vehicle adoption and reduce emissions.

Barth, Wu, and Boriboonsomsin [1] describe how vehicle (collision avoidance and wireless communication), traffic management (traffic monitoring, traffic incident management, integrated corridor management, and travel demand management), and travel information (route guidance, geo-location, and electronic payment) systems can reduce vehicle kilometers of travel and low-speed/ congested driving resulting in greenhouse gas emissions reductions. They describe environmental ITS research programs in the USA and Europe and the advances these initiatives have provided towards lower environmental impact driving.

Martin, Chester, and Vergara [6] explore how the use of life cycle assessment (LCA) has been applied across feedstock-tobiofuel pathways and discuss how attributional and consequential LCA differ in the context of these analyses. The authors present a review of LCA research that evaluates the environmental impacts of agrarian crops, herbaceous plants, and municipal waste as well as newer feedstocks such as algae and seaweed. They characterize the debate over the applicability of attributional and consequential LCA to address policy questions, as LCA has increasingly been used to measure the success of performancebased environmental regulation. Using an example based on an organic waste feedstock, Martin et al. conclude by proposing a generalized biofuel system boundary diagram design that can clearly convey the boundaries and links between attributional and consequential components of any LCA.

\section{Conclusion and Outlook}

The research presented in the articles in this special issue shows that there are significant efforts underway to proactively understand the environmental impacts of disruptive technologies, changing travel behavior, and alternative energy sources. This proactive research may lead to technology designs and deployment strategies that ensure that environmental impacts are reduced and unintended tradeoffs are avoided. 


\section{References}

1. Barth, M., Wu, G., Boriboonsomsin, K. (2015). Intelligent transportation systems and greenhouse gas reductions. Current Sustainable/ Renewable Energy Reports, Volume and Issue Forthcoming. doi:10. 1007/s40518-015-0032-y.

2. Greenblatt, J., Shaheen, S. (2015). Automated vehicles, on-demand mobility and environmental impacts. Current Sustainable/Renewable Energy Reports, Volume and Issue Forthcoming. doi:10.1007/ s40518-015-0038-5.

3. IEA. Transport, energy, and $\mathrm{CO} 2$ : moving towards sustainability. Paris: International Energy Agency; 2009.

4. Jeon CM, Amekudzi AA, Guensler RL. Sustainability assessment at the transportation planning level: performance measures and indexes. Transp Policy. 2013;25:10-21. doi:10.1016/j.tranpol.2012. 10.004 .

5. Kuhlman T, Farrington J. What is sustainability? Sustainability. 2010;2(11):3436. doi:10.3390/su2113436.

6. Martin, E., Chester, M., Vergara, S. (2015). Attributional and consequential life-cycle assessment in biofuels: a review of recent literature in the context of system boundaries. Current Sustainable/ Renewable Energy Reports, Volume and Issue Forthcoming. doi: 10.1007/s40518-015-0034-9.

7. Nealer, R., Hendrickson, T. (2015). Review of recent lifecycle assessments of energy and greenhouse gas emissions for electric vehicles. Current Sustainable/Renewable Energy Reports, Volume and Issue Forthcoming. doi:10.1007/s40518-0150033-x. 